\title{
The Effectiveness of Aid to Kenya: A Case Study
}

\author{
Alex Duncan ${ }^{1}$
}

\section{The Macroeconomic Context}

Kenya's is an open trading economy (exports plus imports were the equivalent of 70 per cent of GNP in 1970) and therefore heavily influenced by conditions over which the country has no control. The major net exports are overwhelmingly agricultural; little diversification has occurred over the past 30 years.

Internally, Kenya operates a comparatively free market, but with heavy government involvement in many activities. Key functions, including the marketing of basic foods, are at least partly carried out by parastatals. The government 'owns shares in textiles, shoes, sugar, tyres, alcohol, pharmaceuticals, canning, mining salt, drilling, paper, hotels, cement, batteries, vehicles, radios, fishing, engineering, beverages and food processing' [Kenya Government 1982].

The 1976/77 coffee boom caused the values of the main export to rise from $\$$ US $107 \mathrm{mn}$ in 1975 to US $\$ 494 \mathrm{mn}$ in 1977, and led government to undertake an ambitious programme of development expenditure and, on the implicit but false assumption that these high revenues would be sustained, to increase recurrent spending by means which included a decreed 10 per cent rise in public-sector employment in 1979. Kenya therefore had far to fall as a result of the 1979-81 oil price rise and the international recession.

\footnotetext{
'Queen Elizabeth House, Oxford. The study on which this paper is based was carried out in 1983 in conjunction with Paul Mosley. University of Bath.

The study set out to assess the effectiveness of official multilateral and bilateral aid to Kenya over the past 10 years, using the criteria of economic growth and the alleviation of poverty. It was based on a visit to Kenya of 3-4 weeks in 1984, during which time interviews were held with senior officials of relevant ministries, with the resident staff of major donors, and with field st aff of some projects. $V$ isits were also made to the headquarters of most major donors in Europe and North America. Cooperation from Government and donors was good in almost all cases.

The many documents consulted, both internal and unrestricted, included those of the Kenya Government, together with many project papers and evaluation documents, and the country analyses prepared by several of the bigger donors.
}

By 1980 both balance-of-payments deficit and budget deficit were over 10 per cent of GNP. Government's response was two-fold.

First, there was heavy external borrowing, together with higher indirect taxes and interest rates, and devaluations over three years amounting to almost 50 per cent against the SDR. Commercial foreign borrowing rose tenfold from 1976 to 1982, and Kenya negotiated four agreements with the IMF between 1979 to 1983. Development expenditures were cut sharply in 1982-83 (by about one-third in real terms). There were marked improvements in both the balance-of-payments and the budget deficit, the latter falling to a provisional three per cent of GNP in 198384 . But the debt service ratio rose to over 20 per cent.

Second, the government tried to use its resources more efficiently. In 1982 it set up the high-level Ndegwa Committee [Kenya Government 1982] which alleged over-extension of government, poor public sector management, and financial indiscipline. Government has taken some steps to implement its recommendations, eg on privatising some public sector activities and decentralising planning and budgeting; but progress overall has been slow.

The role of aid in helping the economy to weather its difficulties over this period can hardly be overstated. External grants and loans rose from 39.9 per cent of government development expenditure in 1979-80 to 84.8 per cent in 1982-83. Particularly significant in allowing even modest growth to be sustained has been the increased balance-of-payments support (see below).

Kenya faces a difficult medium term. The agricultural sector will be crucial in employing and feeding most of the rapidly growing population, and as a principal foreign-exchange earner. But the easy options for raising agricultural value (spare land of medium to good potential, added scope for switching to higher- 
value field crops) are by and large used up; and the international price prospects for the major exports, tea and coffee, are for medium-term stagnation or even decline. Progress in future will depend on policies and institutions that support intensification of production and broad-based generation of incomes.

The single most critical issue is likely to be the distribution of land. Evidence from Kenya's Integrated Rural Surveys shows that, analysed separately over the seven main ecological zones in which crop farming is widespread, holdings of less than 0.5 ha. produce on average a massively higher value per unit area, and use massively more labour (in each case by a factor of 20 to 30 ), than holdings of over $8 \mathrm{ha}^{2}$ Such data should be interpreted with caution (even within each zone, ecological variations may account for part of the differences; and some enterprises, such as breeding improved stock, do not lend themselves readily to small-scale operation). But Kenya's population, currently growing at around four per cent pa, is unlikely to be fed or employed unless - through legislation, political change, or the development of a more effective rental market in land - larger agricultural units are subdivided. ${ }^{3}$

\section{Aid and Donor Coordination}

Kenya is Africa's third biggest aid recipient (after Sudan and Tanzania) with US $\$ 472 \mathrm{mn}$ Overseas Development Assistace (ODA) in 1982. There are about 48 multilateral and bilateral donors (including UN technical agencies, but excluding NGOs) diverse in priorities and procedures, although some 85 per cent of aid comes from the top 10. The World Bank (including IBRD funds which, while not counting as ODA, incorporate a concessional element) is the largest single donor and has a unique role in undertaking country and sector analysis. Although they share broadly developmental objectives, donors' motives (as in other recipient countries) are a mix of commercial, geo-political, bureaucratic and humanitarian, the relative importance of these varying by donor. In addition Kenya is an important test for an open-economy model of development.

The diversity of donors is a useful source of ideas where much remains to be learned about what is effective; but there is also a negative side. The plethora of funds confuses planning and budgeting, introduces

\footnotetext{
2 The dominant importance of holding size is underlined in several papers. including Tidrick (1979): Livingstone (1981); and Hunt (1984).

${ }^{3}$ Data on the current distribution of land by holding size are rather unsatisfactory. Farms of over 20 ha. may account for a little over half of the total arable area, although this is open to question given unrecorded changes in ownership and farm size over the past decade.
}

different procedures for aid management (including procurement and disbursement), and worsens the tendency of aid-tying to multiply types of equipment and to exacerbate training and maintenance problems. Thus there were reported to be 18 different makes of water pump in use, many supplied by aid. Some of these negative effects would be neutralised by effective coordination procedures, but the record of both government and donors in this respect is poor. There has been no effective mechanism for encapsulating the aggregate effect of about 600 projects [UNDP 1983], all of which compete for counterpart finance, manpower and administrative capacity. As a result many, perhaps most, projects suffer from lack of key counterpart contributions.

There were reportedly two short-lived efforts during the 1970 s to set up an aid coordinating mechanism, and in 1984 there was a promising initiative arising from the Consultative Group, involving sectoral committees chaired by government and attended by interested donors. The future of the effort, however, remains in the balance. Effective coordination demands a constant effort, and it runs counter to the immediate interests of some participants: sectoral ministries want to notch up as many projects as possible; donors pursuing commercial interest tend to break ranks; and individual donor officials have 'pet' projects. Still, effective aid coordination is possible; in Kenya the disadvantages of the multiplicity of donors and projects whose aggregate effect is not necessarily tailored to the needs of the country will persist until an effective aid management system is in place. This will not happen until the Kenya government decides to take and sustain the initiative. This has not yet happened.

\section{The Shift to Programme Aid and Policy Dialogue}

Aid goes mainly to agriculture (an estimated 22.8 per cent of commitments in 1982), transport (22.3 per cent), non-project (programme) aid (11.0 per cent), and water and education ( 8.0 per cent each) [UNDP 1983]. The most significant trend in recent years has been the growth, especially in the late 1970 s and early 1980 s, in the proportion being committed as non-project aid (for the UK from 16 per cent in 1972 to 26 per cent in 1983; for the US from 32 per cent to 50 per cent; for the Netherlands from 14 per cent to 25 per cent; and for Sweden from 4 per cent to 12 per cent). This has happened for three main reasons. First, at a time of stringency, maintenance of existing investments received higher priority over embarking on new ones; thus most donors responded to government's budgetary problems by shifting aid towards recurrent costs, not only through programme aid, but also through blurring the capital-recurrent distinction by, 
for instance, covering recurrent costs in subsequent project phases. Second, donors came to feel that the limit of the Kenyan public sector effectively to manage more projects had been reached. Third, several major donors (including the US, UK, and World Bank) had come to the view that institutional and policy reforms were crucial to sustained economic performance and to effective project implementation, and that only programme aid could provide the necessary leverage.

Conditionality is not new. Conditions have always been attached to project aid, normally specific to implementation of the project, but occasionally sectoral when associated with large projects (eg a condition of the Second Livestock Project in Kenya was that government would remove all price controls on meat). And Kenya has experience of IMF conditionality. But what is new is the intensity and range of conditions that have been attached to aid in 1981-5. The most significant elements of programme aid recently have been the two Structural Adjustment Loans (SALs) of the World Bank, sign ificant not only for their size (\$US $185.9 \mathrm{mn}$, fully disbursed between 1980 and 1984), but also because the policy conditions to some extent set the agenda for other donors too. Thus US and UK programme aid was contingent on Kenya and the World Bank agreeing on the SALs.

The SAL conditions sought to liberalise trade internally (most importantly the grain trade during SAL II) and externally (replacing import quotas with tariffs and reducing the effective rate of protection), and to promote non-traditional exports. There were also modest conditions concerned with strengthening national population policy and addressing land issues. All these conditions were consistent with previous Kenya Government statements of policy, and - more than previous project conditions, or IMF macroconditionality - addressed the broad economic framework, so that the link was less explicit between the conditions and the variables (economic growth in particular) they were intended to influence.

The record of implementation of the SALs in Kenya reflects a lesson that emerges from donors' experience in other countries too, namely that aid is often ineffective in bringing about a sustained change of policy to which the recipient government (or influential elements within it) is not already committed, but that it can be more effective if it is helping to underwrite the costs of difficult change to which the recipient is favourably predisposed [Cassen 1986]. Thus in Kenya, although most of the changes proposed under SAL were nominally already policy, in fact in key respects (eg grain marketing and imports) important interests were not committed to the liberalisation envisaged under the SAL and policy did not change significantly. These interests included provincial and district officials in food surplus areas who valued the power to keep food prices low locally, as well as private individuals engaged in trading grain who benefited from price differentials. For some measures (eg import liberalisation and population) government took the steps necessary to comply with the letter of the agreements (reducing reliance on import quotas, setting up a population council) but avoided substantive change (protection remained high). The lesson from Kenya is that donors should not underestimate the obstacles to influencing policy through direct leverage.

\section{Some Sectoral Experience with Project Aid}

The Kenya study could not cover all sectors and projects. But evaluations of numerous projects were reviewed, and both authors had independent knowledge of some projects. Projects in five sectors were included in the study - agriculture, transport, energy, rural water, and population. The record is mixed; whereas up to about the mid-1970s Kenya had the reputation among donors of making as effective a use of aid funds as any other country in Africa, the performance worsened rapidly and by the early $1980 \mathrm{~s}$ aid projects in Kenya had a bad record.

Such a conclusion inevitably has strong subjective and unquantified elements. There are two important gaps in the evaluation material. First, few projects (exceptions being the Rural Access Roads Programme - see below - and some rural water projects) are evaluated for impact on low-income groups; thus we could not reach conclusions as to the direct impact of aid on poverty. Probably, some initiatives (the Rural Access Roads Programmes, hybrid maize varieties which were widely adopted by small farmers) had beneficial effects on some low-income groups, if not the poorest; but in some cases (eg in the sugar industry, or rural water) less capital-intensive technologies might have generated incomes or provided services more widely.

Second, the paucity of 'impact studies', which assess projects some years after donor support ends, means that long-term effects are incompletely known. But the government's difficulty in providing for recurrent costs, together with the fragmentary evidence that many projects in Kenya are not sustained [see the Introduction to this Bulletin), underpin current donor concern with this topic.

In agriculture there have been successes, many associated with initiatives of the $1950 \mathrm{~s}$ and $1960 \mathrm{~s}$, and reflecting the fortunes of the sector as a whole growth of 4.6 per cent pa from 1963-72, 2 per cent from 1972-77, and sharp fluctuations thereafter [World Bank 1984]. Successes include support for smallholder 
agriculture through extending hybrid maize, for the Kenya Tea Development Authority (with some 130,000 smallholder growers), and for smallholder coffee production. But the ambitious, multi-component national rural development and livestock projects begun in the early to mid-1970s ran into difficulties, in part associated with their scale and institutional complexity (in particular their demands upon inter-ministry coordination). The evaluation reports on these projects in the early 1980s found low or negative returns, and little success in institutionbuilding. No more projects of this type are envisaged.

Another set of 10 multi-sector projects, covering 13 districts, grouped under the Arid and Semi-arid Lands (ASAL) programme, have had mixed results. In part, their difficulties arise because low and unreliable rainfall makes investment risky and high-input farming precarious. But inst itutionally they have done better than the national integrated projects, largely because inter-sector coordination is more readily achievable at the district than at the national level. If the momentum of decentralising planning and budgeting to the districts is kept up, this model should be increasingly relevant. But these projects (typically involving roads, health, agriculture, livestock) do still need national inter-sectoral direction. Experience has shown that this cannot be achieved if the 'parent' ministry is sector-specific; it must in effect be the Office of the President or the Ministry of Finance and Economic Planning, even at the risk of these projects being given a low priority at senior levels.

The disappointing record of many agricultural projects has led in two directions. There are fewer projects in the pipeline, especially for the public sector (USAID, for instance, was envisaging only one, in research). And the new projects are organisationally simpler - eg the World Bank's National Extension Project, a follow-up to the unsuccessful Second Integrated Agricultural Development Project.

In the energy sector, there is a striking discrepancy: some 90 per cent of donor funds for the sector are used for commercial energy sources [UNDP 1983] which account for only 21 per cent of final demand for energy, the bulk of which is met from charcoal, fuelwood, and crop wastes [Beijer Institute 1984]. Thus the needs of low-income groups in particular are being neglected. Partly as a result of this, Kenya faces an ecological crisis by the end of the century [Beijer Institute 1984: 177]. Nevertheless, aid interventions in commercial energy have been beneficial. Through farsighted programmes, the only increase in electricity generation has been an 11.9 per cent annual increase since 1975 in hydro-electrical capacity [CIDA 1984], apart from a promising geo-thermal scheme. But for this, the already heavy burden of liquid fuel imports
(58 per cent of non-petroleum exports in 1982) would have been worse.

We did not comprehensively review aid for the transport sector, but did look at an innovative and effective Rural Access Roads Programme (RARP). Starting in 1970, the roads component of the Special Rural Development Programme tested capital- and labour-intensive methods of rural road construction; the latter were found to be fairly successful. They were therefore incorporated into the RARP, supported by six donors, and coordinated by a relatively effective ministry, from the mid-1970s covering 23 districts (over half the total). A labour-intensive maintenance system was added later, and by 1983 some $7,000 \mathrm{~km}$ had been constructed and $3,000 \mathrm{~km}$ gravelled. Evaluation studies, although not complete, indicate beneficial income generation and distribution effects, and a reduction in long-term out-migration [Kenya Government 1983]. The RARP is not typical of funds spent on transport, which may in total be too large relative to other sectors, and in nature too capitalintensive. But the RARP does point up lessons for designing and managing transport projects.

Rural water, by contrast, is a less good advertisement for aid. The sector absorbed 9 per cent of all aid in 1965-84; yet at least 89 per cent of the rural population still lacks access to a protected water supply. The problem arises from inappropriate high-cost technology with excessive capital intensity; too little provision for maintenance; interrupted supplies of fuel; and political pressures governing the location of schemes. Donors have disagreed on the best method for charging, and cost-recovery is low; about 60 per cent of consumers are unmetered, and pay for about 15 per cent of the total cost of water. By contrast with rural roads, the ministry is less effective, and there has been much less sustained testing of alternative approaches, let alone implementation of those proved to work.

As for population activities, these absorbed only 3.2 per cent of total aid to Kenya between 1974 and 1983 - in striking contrast to the donors' conviction that Kenya's 4 per cent rate of growth of population is its main problem. But this aid seems to have been well used. Donors have generally coordinated well, have assisted constructively in the formulation of policy, but have kept a low profile, and have funded fairly effective delivery systems. But population growth has not yet started to slow down; much more needs to be done.

The explanation for the small proportion of aid for the purpose is largely that the Kenya government did not ask for such help until 1974 and even then on a very modest scale. Only after the change of leadership was 
there a national political commitment to slower population growth, and even this is not universally shared by politicians. The main problem is not lack of demand for family planning services. In Kenya, as in many other primarily agricultural ldc's there is good reason for many people to prefer large families, as is borne out by national survey data. But discussions with government and donor officials, confirmed by a visit by one of us [Mosley] to a clinic offering family planning services, indicated that there is unmet demand. A good use of more aid funds would be an expanded public information programme.

Overall, our (incomplete) review of sectors indicated a need for a continuing learning process, involving both donors and the government, on what works and what doesn't, and on how to manage aid effectively.

\section{Conclusions}

Inevitably, in view of the diversity of aid to Kenya, we cannot put a figure on 'how much works'. Since independence, important social indicators (life expectancy, literacy) have shown an improvement; and aid funds and technical assistance have played a role in this. Nevertheless, extensive poverty and undernutrition show no sign of disappearing. And many aid-supported interventions fail.

Why does a significant proportion of projects in all sectors fall short of what was expected? First, the financial crisis of the early $1980 \mathrm{~s}$ and the drastic cuts in development expenditure devastated project implementation; lacking an effective national aid management and budgeting system (a deficiency since being addressed by government with donor support), government did not rank projects in order of priority, and cuts were therefore made across the board, sometimes by eliminating crucial items. Second, as the Ndegwa Committee found, the efficiency of the administration in Kenya has fallen. Third, aid coordination is poor; there are discrepancies between the uses of aid funds and the needs of the economy, especially of low-income groups. Fourth, both donors and the recipient government have shown themselves to be fairly indifferent to the needs of the very poor, subscribing, if to any approach, to an attenuated version of 'trickle-down'.

Fifth, donors have been unrealistic in drawing up their policy prescriptions; these should not only be appropriately designed in detail for Kenya's needs, but should also contribute to a constructive relationship, rather than to confrontation, between donor and recipient. In particular, donors need to improve the policy dialogue by building up the Kenya Government's capacity for planning and policy analysis. Some support of this kind is being given, for instance through the multi-donor institutional projects in the Treasury and Ministry of Agriculture; but many other projects should give more weight to building capacities, even at the expense of short-term achievements. Finally, donors should minimise the influence of the non-developmental aims of their aid programmes; in particular, even if they cannot do away with aid tying, they need to reduce the consequent distortions.

\section{References}

Beijer Institute, 1984, Energy and Development in Kenya: Opportunities and Constraints, P. O'Keefe, P. Raskin and S. Bernow (eds.) Beijer Institute, Royal Swedish Academy of Sciences, Stockholm and the Scandinavian Institute of African Studies, Uppsala

Cassen, R. (ed.), 1986, Does Aid Work?, Oxford University Press

CIDA, 1984, Kenya: energy secior review, Report prepared for CIDA by R. L. Walker and Partners Ltd., January

Hunt, D., 1984, The Impending Crisis in Kenya: the Case for Land Reform, Gower, Aldershot

Kenya Government, 1982, Report and Recommendations of the Working Party on Government Expenditures (the Ndegwa Report), Government Printer, Nairobi, July

- 1983, Status Report on Analysis of Impact Data (Rural Access Roads Programme), Ministry of Transport and Communications, Nairobi, October

Livingstone, I., 1981, Rural Development. Employment and Incomes in Kenya, ILO/JASPA, Geneva

Tidrick, G., 1979, Kenya: Issues of Agriculural Development, MEPD, Nairobi

UNDP, 1983, Compendium on Development Cooperation in Kenya as of December 3/s1. 1982, Nairobi

World Bank, 1984, Kenya: Agricultural Seclor Report, Report no. 4629-KE (2 vols.) Washington DC 